\title{
Correspondence
}

\section{Russian stamp to honour physicist}

Russia has just issued a postage stamp to mark the centenary of the birth of the brilliant physicist and cosmologist Yakov Zel'dovich (1914-87).

Among his many achievements, and despite never having received a university degree, Zel'dovich developed the theories of nuclear chain reactions and of the gravitational lens (see R. A. Sunyaev (ed.) Zel'dovich: Reminiscences Chapman \& Hall/CRC; 2004).

As a theoretician, he was involved in the creation of Soviet nuclear weapons - the atomic bomb in 1949, with Lev Landau, and the hydrogen bomb in 1953, with Andrei Sakharov. Like Robert Oppenheimer in the United States, he met with government opposition when he declined to continue working on weapons development.

Moving over to astrophysics, Zel'dovich made seminal contributions in gravitational instabilities and in cosmological fluctuations, with the SunyaevZel'dovich effect being among the best known. In 2001, an asteroid, 11438 Zel'dovich, was named in his honour.

Renad I. Zhdanov Kazan Federal University; and Sholokhov Moscow State University for the Humanities, Russia.

Pascal Chardonnet University of Savoie, Annecy, France. zrenad@gmail.com

\section{White possums must stay cool to survive}

It is ironic that Australia, one of the world's highest carbon emitters per capita, is giving up on a hard-won plan to reduce its greenhouse-gas emissions (see Nature 511, 392; 2014) just as climate change could be about to claim one of its rarest and most iconic animals - the white lemuroid ringtail possum (Hemibelideus lemuroides).

The white possum was once

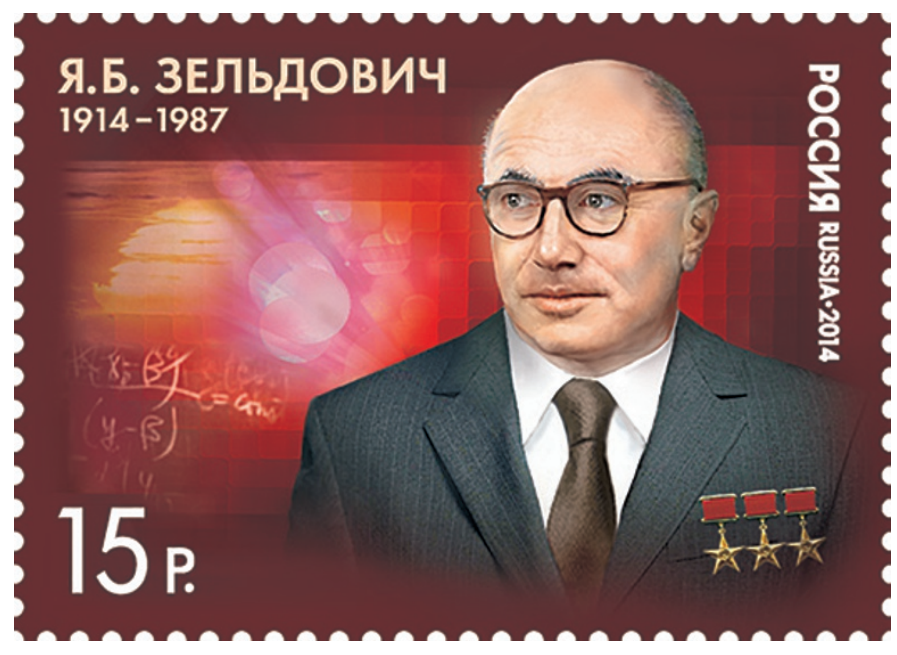

abundant in cool rainforests on Mount Lewis in northern Queensland, but its population collapsed abruptly following a severe heatwave in 2005. Today, just a handful of individuals are left (see J. Chandler New Scientist Issue 2980, 42-45; 2014).

Tropical mountains are full of endemic species that have adapted to cooler local climates and are particularly vulnerable to heatwaves and other extreme weather associated with climate change (see go.nature.com/ vqskfa).

It has therefore been suggested that the white possum might be a more sensitive indicator of climate change than the polar bear (W. Laurance New Scientist Issue 2690, 14; 2009). But first the temperature of its habitat must be stabilized so that its numbers can be restored. William F. Laurance, Susan Laurance James Cook University, Cairns, Australia.

bill.laurance@jcu.edu.au Christine Milne Parliament House, Canberra, Australia.

\section{Mexican GM maize rift is not so simple}

You rightly point out that the issue of genetically modified (GM) maize (corn) is more sensitive and complex in Mexico than in other countries (Nature 511, 16-17; 2014), but you owe readers a more in-depth and balanced view.

The rift in Mexico's scientific community over GM maize is not directly related to the legal challenge you discuss. It is a result of the commercial push to plant GM maize before the benefits and risks, and the costs to Mexican society, have been fully assessed.

The possibility of producing maize that is tolerant to drought and frost, a claim you report from government-funded researchers, could indeed help to restore Mexico's capacity for growing its own maize. However, commercial cultivars in Mexico (25\% of total area) have limited reach, even after more than 60 years of breeding (see, for example, S. Brush and H. Perales Agr. Ecosyst. Environ. 121, 211-221; 2007). More than two million households rely on traditional landraces for food security (H. Eakin et al. Dev. Change 45, 133-155; 2014), and the global prevalence of insecticideproducing and herbicide-tolerant GM products is at more than $98 \%$ after almost 20 years (see go.nature.com/jyux8p). These factors mean that such claims need to be realized and qualified if they are to be taken seriously.

Those seeking commercial acceptance of GM maize still need to convince key groups in Mexican society, including scientists, that the benefits of planting it will outweigh the risks and social costs. There is more to maize in Mexico than productivity and business, and it is not only scientists and seed companies who have rights. Hugo Perales El Colegio de la Frontera Sur (ECOSUR), San Cristóbal, Chiapas, Mexico. hperales@ecosur.mx

\section{Create ethics codes to curb sex abuse}

A survey published last month found evidence of alarming levels of sexual violence (towards $26 \%$ of women and $6 \%$ of men) in the course of fieldwork by life scientists (see Nature http:// doi.org/t3n; 2014). Meanwhile, more than 50 US highereducation institutions are under investigation for their handling of complaints of such incidents. As a rape survivor and scientist, I suggest measures that could help to counteract this situation.

Scientific research organizations should draw up professional codes of ethics, akin to those of the Modern Language Association of America and the American Historical Association, with explicit provisions that denounce sexual harassment and discrimination on the basis of race, gender or sexual orientation.

A national framework that academic, industrial and government institutions could sign or adapt would be an important step. Such proactive strategies would prevent interference with the core work of researchers. In the United Kingdom, for example, the Athena SWAN Charter outlines a series of best practices to further and protect women's careers (see go.nature.com/mkxlr8).

Institutions must make clear the repercussions for students and employees who transgress, and provide a mechanism for consistent enforcement (such as an adjudication committee) that would complement any legal redress.

Margaret C. Hardy University of Queensland, Brisbane, Australia. m.hardy@imb.uq.edu.au 